\title{
Mismatch repair deficiencies transforming stem cells into cancer stem cells and therapeutic implications
} Minal Vaish*

\author{
Address: Department of Biochemistry, University of Lucknow - 226007, U.P., India \\ Email: Minal Vaish* - minal14@yahoo.com \\ * Corresponding author
}

This article is available from: http://www.molecular-cancer.com/content/6/1/26

(C) 2007 Vaish; licensee BioMed Central Ltd.

This is an Open Access article distributed under the terms of the Creative Commons Attribution License (http://creativecommons.org/licenses/by/2.0), which permits unrestricted use, distribution, and reproduction in any medium, provided the original work is properly cited.

\begin{abstract}
For the exceptional self-renewal capacity, regulated cell proliferation and differential potential to a wide variety of cell types, the stem cells must maintain the intact genome. The cells under continuous exogenous and endogenous genotoxic stress accumulate DNA errors, drive proliferative expansion and transform into cancer stem cells with a heterogeneous population of tumor cells. These cells are a common phenomenon for the hematological malignancies and solid tumors. In response to DNA damage, the complex cellular mechanisms including cell cycle arrest, transcription induction and DNA repair are activated. The cells when exposed to cytotoxic agents, the apoptosis lead to cell death. However, the absence of repair machinery makes the cells resistant to tumor sensitizing agents and result in malignant transformation. Mismatch repair gene defects are recently identified in hematopoietic malignancies, leukemia and lymphoma cell lines. This review emphasizes the importance of MMR systems in maintaining the stem cell functioning and its therapeutic implications in the eradication of cancer stem cells and differentiated tumor cells as well. The understanding of the biological functions of mismatch repair in the stem cells and its malignant counterparts could help in developing an effective novel therapies leaving residual nontumorigenic population of cells resulting in potential cancer cures.
\end{abstract}

\section{Background}

Gurdon first introduced the concept of stemness state of the cells while successfully achieving the generation of all cell lineages of a living tadpole after transferring the nuclei from intestinal epithelial cells of feeding Xenopus tadpoles to activated enucleated eggs $[1,2]$. These types of cells were later on characterized as indispensable entities, identified in multicellular organisms. The stem cell phenotype is contributed by the unique features that include (1) self-renewal which means that after cell division, one of the daughter cells must have the same genetic material as that of the parent cell, (2) differentiation i.e. capability to differentiate into multiple lineages and (3) extensive proliferation. The adult stem cells are identified in variety of tissues and organs in humans including - bone marrow, brain, skin/hair follicles, heart, lung, intestine, liver, pancreas, mammary glands, ovaries, prostrate, and testis [3].

The multipotency of stem cells to maintain tissue homeostasis and its differentiation into mature cell types is under a tightly controlled system and is associated with restricted expression profile. The expression of transport proteins - ABC (ATP-binding cassette) transporter proteins and multidrug resistant proteins that protect cells against toxins and are associated with the efflux of xeno- 
biotic toxins, low rate of cell division and active DNA repair are the innate properties of normal development of stem cells. Besides hormonal stimulation, DNA damage is one of the key factors for stem cell activation. DNA accumulates errors either from environmental factors, which could be the exposure to radiation, chemicals or drugs, viruses and bacteria or DNA replication errors [4]. This would result in complex cellular responses that include loss of cell cycle regulation, transcription induction and DNA repair mechanisms for maintaining genomic and chromosomal stability. But in absence of efficient DNA repair machinery, the stem cells accumulate harmful mutations and become resistant to apoptosis resulting in the loss of genome or instability, which ultimately lead to malignant transformation of stem cells [5]. Table 1 features the stem cell activation types, which transforms them into different cancer types $[4,6]$. Each stem cell activation type is exemplified with a single cancer type in the Table 1 , however many could be associated. The progenitor cells also known as transit - amplifying cells arise from normal stem cells have replicative ability but not selfrenewal capacity. Mutations in these progenitor cells help in regaining self-renewal property and become cancerous (Fig 1).

Cancer stem cells (CSCs) were first identified in 1990s in hematological malignancies, mainly acute myelogenous leukemia (AML) and also in other subtypes like AML M0, M1, M2, M4 and M5 and chronic myeloid leukemia (CML), acute lymphoblastic leukemia (ALL) and multiple myeloma [7]. CSCs are also known in solid tumors like breast, brain, lung, prostrate, testis, ovary, stomach, colon, skin, liver, pancreas [8-10]. These tumor cells have a selfrenewal property but undergo aberrant differentiation and constitute the heterogeneous population of tumor cells [11].

In the hematopoietic and solid tumors side population (SP) containing CSCs constitute the fraction of total population of cells that shows that CSCs is a common phenomenon for all the malignancies. SP can be identified by the efflux of fluorescent dyes by $\mathrm{ABC}$ transporter proteins which are the major multidrug resistant genes. In the absence of DNA repair capacity, the drug resistant pluoripotent cells accumulate mutations and show increased cell survival [12].

\section{DNA repair}

To maintain the genomic integrity and normal functioning of stem cells, several DNA repair pathways come into interplay and provide the robust defense to the cell. Absence of these repair processes have a great impact on the diminution of stem cells and increased chance for

Table I: Stem cell activation types transforming normal stem cells into cancerous stem cells

\begin{tabular}{|c|c|c|}
\hline Stem cell activation type & Target tissue/organ & Cancer type \\
\hline Naturally activated stem cell: Inactivation of RBI gene & Retinoblasts & Retinoblastoma \\
\hline Loss of tumor suppressor genes ( $\mathrm{p} 53)$ & Breast & Breast \\
\hline Expression of oncogenes (ras, myc) & Brain & Brain \\
\hline Hormonal stimulation: estrogen & Breast & Breast \\
\hline Inflammation: Crohn disease, inflammatory bowl disease, result in activated cell growth & Colon & Colon \\
\hline Viral infection: Hepatitis $B$ and $C$ cause inflammation and extensive cirrhosis & Liver & Liver \\
\hline Exposure to irritants like tobacco, asbestos cause inflammation & Lung & Lung \\
\hline Bacterial infection: Helicobacter pylori and metal dust exposure cause inflammation & Stomach & Stomach \\
\hline Loss of miRNA genes (miRI5 and miRI6) which act as tumor suppressors & Bone marrow & Chronic lymphoid leukemia \\
\hline Enforced expression of miR I7-92 cluster which acts as oncogenes & Bone marrow & B cell lymphoma \\
\hline $\begin{array}{l}\text { DNA methylation at } 5 \text {-position at cytosine residue within CpGs by Dnmtl (maintenance } \\
\text { methyltranferase), Dnmt3a, 3b (initiate de novo methylation), Dnmt2 }\end{array}$ & Colon & Colorectal \\
\hline $\begin{array}{l}\text { Methylation dependent repression of transcription by binding of methyl CPG binding proteins- } \\
\text { MECP2, MBDI-4, Kaiso to DNA }\end{array}$ & Colon & Colorectal \\
\hline $\begin{array}{l}\text { Histone methylation by H3K4 Mtases, H3K9 Mtases, Suv39hI/Suv39h2, G9a, Eu-H Matsel, } \\
\text { ESET/SETDBI }\end{array}$ & Prostate & Prostate \\
\hline $\begin{array}{l}\text { Histone acetylation via histone acetyltransferases (HAT) include Gcn5 family proteins, MYST } \\
\text { protein, p300/CBP, TAF250, ACTR/SRCI nuclear receptor cofactors mediate transcriptional } \\
\text { activation }\end{array}$ & Breast & Breast \\
\hline $\begin{array}{l}\text { Histone deacetylation silences gene expression via HDAC I family, HDAC II family, Sirtuin } \\
\text { family (Sir2) }\end{array}$ & Bone marrow & Acute myeloid leukemia \\
\hline $\begin{array}{l}\text { Blockage of DNA accessibility to transcription factors by polycomb group proteins which } \\
\text { include Polycomb repressive complexes - PRCI contains Cbx, Mph, Ring, Bmi-I, Mel/ } 8 \text { and } \\
\text { PRC2 contains Ezh2, SuzI } 2 \text { and Eed }\end{array}$ & Bone marrow & B and $T$ cell lymphoma \\
\hline $\begin{array}{l}\text { Alteration in chromatin accessibility to proteins and restriction endonucleases by the } \\
\text { disruption of association of histones with DNA using the energy by ATP hydrolysis via ATP } \\
\text { dependent remodeling complexes (SWI2/SNF2 protein, ISWI enzymes, Mi-2/NuRD proteins }\end{array}$ & Bone marrow & Acute myeloid leukemia \\
\hline
\end{tabular}


<smiles>C1CCCCCCCCCC1</smiles>

Self renewal property

Normal stem cell

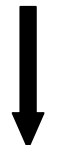

Genetic and epigenetic alterations

(Hormonal stimulation, DNA damage)

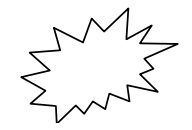

Stem cell activation

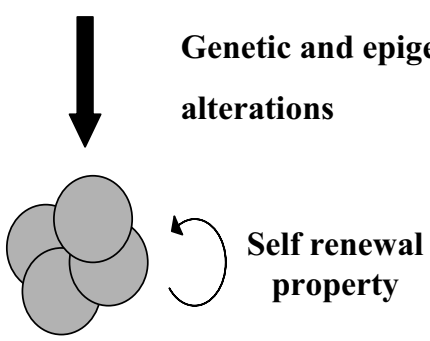

Cancer stem cells
Progenitor cells/ Transit-amplifying cells
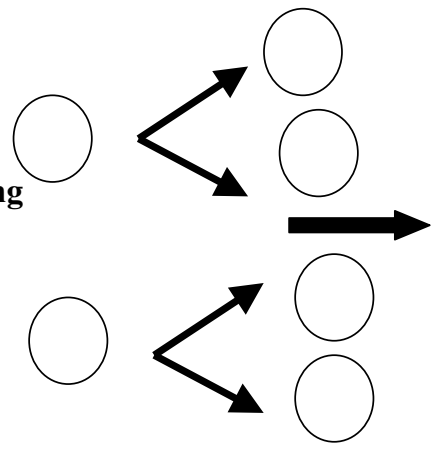

Differentiated mature cell type

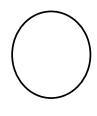

\section{Mutations}

\section{Differentiated primary tumor}

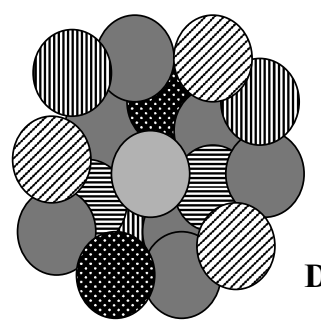

\section{Figure I}

Development of cancer stem cells from the normal stem cells and progenitor cells. Accumulation of DNA errors in normal stem cells or progenitor cells are activated to generate a cancer stem cells (CSCs) that further generate a primary tumor constituting CSCs and other tumor cells.

stem cell differentiation and malignant transformation due to altered gene expression.

(a) O6- alkylguanine DNA alkyl transferase (AGT) repair

AGT repair is a DNA repair protein encoded by MGMT (O6-methylguanine DNA methyltransferase) removes DNA adducts from $\mathrm{O} 6$ methylguanine. The failure in the repair system results in G to A transition and DNA strand break observed in hematopoietic tumors, breast, ovarian and retinoblastomas $[13,14]$.

\section{(b) Nucleotide Excision Repair (NER)}

In NER, the damaged DNA bases are recognized by XPC (xeroderma pigmentosum complementation group $\mathrm{C}$ ) and RAD23B whereas XPA, RPA (replication protein A), RNA polymerase II transcription factor $11 \mathrm{~A}$ and XPG excise the fragment of 27-30 nucleotides surrounding the damaged bases. The gap is further restored by DNA polymerases and ligases and replaces it with the correct sequence. Defective NER leads to xeroderma pigmentosum (skin cancer) [15].

\section{(c) Base Excision Repair (BER)}

It comprises of short and long patch pathways where DNA glycosylases generate apurinic/apyrimidinic (AP) followed by its 5 ' excision by AP endonucleases (APE-1) and remove damaged bases. Double-stranded breaks have the potential to be the most disruptive form of DNA damage $[16,17]$.

(d) Non-Homologous DNA End-Joining (NHEJ) repair

Double-stranded breaks have the potential to be the most disruptive form of DNA damage. The DNA double strand breaks (DSBs) produced by free radicals generated during 
oxidative respiration, ionizing radiation, DNA replication, malfunction of recombination activating gene complex during $\mathrm{V}(\mathrm{D}) \mathrm{J}$ (variable region, diversity regionjunction region) recombination in $\mathrm{T}$ and $\mathrm{B}$ lymphocytes are brought in closed proximity by Ku70-Ku80 heterodimer and kinase activity by DNA dependent protein kinase catalytic subunit (DNA-PKcs) of DNA-PK complex followed by its ligation by XRCC4-DNA ligase IV, SCID (Severe Combined Immunodeficiency) is associated with defective NHEJ repair system [15].

\section{(e) Homologous Recombination (HR) repair}

The DSBs are repaired by misalignment, deletions, and rearrangement. ATM, a PI-3 Kinase binds DNA and phosphorylates multiple proteins. BRCA1 activated by ATM (ataxia telangiectasia) facilitates BRCA2 and RAD51 binding of the overhang followed by the attraction of RAD52/ RAD54 with the help of BLM/WRN proteins. The homologous recombination is facilitated by large protein complexes at the DSBs. High incidence of leukemia, breastovarian, Werner's and Bloom's syndrome with severe premature aging and cancer is seen in defective HR repair system $[18,19]$.

\section{(f) Mismatch Repair (MMR)}

It is a genome surveillance system in bacteria, yeast and mammals by maintaining genomic integrity. The MMR pathway is the form of DNA repair responsible for the elimination of specific mismatched and/or unmatched bases and insertion-deletion loops (IDLs) where DNA synthesis is liable to errors, either as a part of DNA replication before cell division, or as part of DNA repair (unscheduled DNA synthesis) [20]. Although DNA polymerases have the ability to identify and correct their own errors, some mistakes are not identified.

Mismatch in eukaryotic DNA is recognized by two heterodimeric complexes of Mut $\mathrm{S}$ related proteins - MSH2/ GTBP (Mut S $\alpha$ ) and MSH2/MSH3 (Mut S $\beta$ ) [21]. Mut S $\alpha$ binds to both base - base mismatches and small ID (insertion - deletion) heterologies whereas Mut $S \beta$ plays major role in repair of larger ID mispairs [22]. Presence of ATP markedly decreases the affinity of Mut $S \alpha$ for an oligonucleotide heteroduplex, an effect also observed with bacterial Mut S. Hydrolysis of ATP facilitates protein - protein interactions and or sliding along with DNA [23]. Recognition of mispair is followed by binding of Mut S $\alpha$ (MSH2/ MSH3) with Mut L related proteins [MLH1/hPMS2 (PMS1 in yeast)] and converts into high molecular weight structure. It also increases the efficiency of Mut $\mathrm{S}$ proteins to recognize the mismatch. MLH1/MLH3 (PMS2 in humans) also forms the complex with Mut $S \beta$ and help in repair of ID mispairs [24].
Proliferating cell nuclear antigen (PCNA) has been identified as DNA polymerase processivity factor and has a role in repair at or prior to excision steps as a strand discriminating factor [25]. Bi - directional threading of DNA through hMut $\mathrm{S}$ heterodimer is continued till the arrest of forward movement of replication fork that occurs via an interaction with PCNA in the polymerase complex. Recently another eukaryotic mismatch repair endonuclease has been identified whose amino terminal domain is involved in binding to fully methylated DNA and carboxyl terminal region is involved in catalysis and complex formation with Mut L homologue MLH1. This protein is named as MED1 (methyl - CpG binding endonuclease 1). The properties of MED1 felicitate it to be a functional homologue of MutH [26].

DNA exonuclease and helicase unwind, nick and degrade the error - containing strand. After dissociation of MMR complex, PCNA, which still binds at the end of error containing primer strand, recruits replication complex and thus re-initiation starts with the help of DNA polymerase.

The mutations characterized by point mutations, insertions or deletions in the length of DNA microsatellite repeat sequences throughout the genome resulting in microsatellite instability (MSI) is a hallmark of defective DNA MMR system which result in malignant transformation [27].

The maintenance of MMR system decreases the error rates by 100 to 1000 fold during DNA replication. Since it has tremendous importance in the carcinogenesis, this review presents a discussion on the role of DNA mismatch repair system as a therapeutic potential in eliminating the cancer stem cells.

\section{MMR deficiency and stem cell defects}

The maintenance and longevity of stem cell phenotype is characterized by the presence of efficient MMR system, which result in accurate DNA replication, restore normal DNA after its damage and remove replication defects at microsatellite sequences by repairing the DNA polymerase slippage products.

The MMR deficiencies because of the mutations in wild type MMR allele with Msh2 $\%$ and Mlh $2 \%$ phenotype, mice develop stem cell-derived-lymphoid malignancies and all lymphoid tumors show MSI [28]. The serial bone marrow transplantation assay was done to compare Msh $2 \%$ primary murine hematopoietic cells with wild type into lethally irradiated mice with temozolomide, a methylating agent. MMR deficiency as evident by MSI was observed in early progenitor colony forming unit (CFU) and $\mathrm{Sca}^{+} \mathrm{Kit}^{+}{ }^{+}$Lin $^{-}$derived clones, which explain the alteration in growth and survival of hematopoietic stem cells and its 
Table 2: Markers expressed in normal and cancer stem cells in humans

\begin{tabular}{|c|c|c|c|c|}
\hline Organ & Cancer type & Normal stem cell markers & Cancer stem cell markers & References \\
\hline Hematopoietic & Leukemia & CD34+CD38-Thyl-Lin- & CD34+CD38- Thyl-Lin- & {$[47,48]$} \\
\hline Breast & Mammary cancer & CD24med & CD $44^{+}$CD24-/lowESA+ ${ }^{+}$Lin $^{-}$ & {$[8,11]$} \\
\hline Brain & Brain tumor & CDI33+ Lin $^{-}$ & CDI33+Nestin & {$[49,50]$} \\
\hline Skin & Melanoma cancer & CD20-CDI66- Nestin- & $\mathrm{CD} 20^{+} \mathrm{CD} 166^{+}$Nestin+ & {$[51,52]$} \\
\hline Prostate & Prostate cancer & $\mathrm{CD} \mid 33^{+} \alpha_{2} \beta_{1}{ }^{\mathrm{hi}}$ & $\mathrm{CD}_{4} 4^{+} \alpha_{2} \beta_{1}{ }^{\text {hiCDI} 33^{+}}$ & [53] \\
\hline Tongue, Larynx, Throat and Sinus & Head and neck squamous cell carcinoma (HNSCC) & CD44- & $\mathrm{CD}_{4} 4^{+}$ & [54] \\
\hline Pancreas & Pancreatic cancer & CD24-CD44-ESA- & $\mathrm{CD} 24^{+} \mathrm{CD} 44^{+} \mathrm{ESA}^{+}$ & [48] \\
\hline
\end{tabular}

long-term repopulation capacity because of accumulation of genomic instability [5]. In another study, colonogenic survival was assayed in Msh2 ${ }^{--}, \mathrm{Msh} 2^{+/+}, \mathrm{Msh} 2^{-/+}$mouse embryonic stem cells following prolonged low level radiation treatment. The cells deficient in active MMR system survive promutagenic genomic insults by alkylating and oxidating agents that contribute to neoplastic transformation as in hereditary non-polyposis colorectal cancer (HNPCC) [29]. The six cases of childhood leukemia are reported where patients are homozygous for MSH2, MLH1 or PMS2 loss of function mutations [30].

The loss of MMR genes directly or indirectly alters signal pathways, loss of strictly regulated expression of cytokine receptors, transcription factors and cell cycle regulation [5]. Unlike normal stem cells the presence of damaged DNA does not activate p53 induced G1 cell cycle arrest and also the repair helicases XPB and XPD fail to functionally interact with p53 [31,32]. This contributes to the loss of stem cell phenotype, a proliferative advantage and cancer stem cell formation.

The mitotic homologous recombination can result in chromosomal translocations, deletions or inversions with deleterious consequences in the adult or during development. Loss of MMR adds up an additional level of genetic instability in a form of chromosomal rearrangements commonly observed in hematological malignancies. High incidence of lymphoma is reported in Msh2 deficient mouse embryonic stem cells [33].

The Msh2 low and deficient mouse ES cells showed poor or complete elimination of repair function and demonstrated the resistance against the toxic effects of an ethylating agent, N-ethyl-N-nitrosourea (ENU). The ENUinduced mutagenicity under the fully or partially deficient conditions accelerated the lymphomagenesis [34]. Toft et al., showed the increase in mutation frequency at Dlb-1 locus due to loss of Msh2 status in normal intestinal cells predispose to malignancy. The increased colonogenicity was observed in Msh2 $\%$ mouse ES cells after exposure to temozolomide but not cisplatin and contributed to failed repair mechanism and apoptosis in a p53 dependent manner [35].
In a study by Fink et al., Msh2\%- mouse embryonic stem cells showed two-fold resistance to the cytotoxic effects of cisplatin as compared to wild type cells [36]. On the contrary, Claij \& Riele found no relation between the MMR capacity of cells and their response to cisplatin in a colonogenic assay in mouse ES cells [37]. However, certain specific changes like mutated p53 [38], increased recombinational repair or increased replicative bypass are collaborated with MMR deficiency in affecting the cytotoxicity of cisplatin.

\section{Therapeutic implications of mismatch repair in cancer stem cells}

In most of the malignancies CSCs constitute less than 1\% of total cell population. They are in quiescent state and most of the conventional chemotherapeutic drug therapies are effective in actively dividing cells, so for complete eradication of CSCs, the therapeutic agents either should kill cells independently of the cell cycle or selectively induce cycling of cancer cells. Moreover, therapy should target pathways uniquely used by CSCs. CSCs express various drug transporter proteins which efflux the cytotoxic drugs and protect them from damage. The inhibitors to these transporters make the CSCs sensitive to chemotherapy. Since normal stem cells also express some of these transporters so non selective inhibition of these multidrug resistant genes also kill normal stem cells. The characterization of stem cells markers would help in identification of CSCs from normal stem cells have important implications in elimination of CSCs by specifically targeting the tumor cells [39]. Table 2 lists the human cell surface markers in normal as well as CSCs, which are used to distinguish the two populations of cells.

The wild type MMR expression blocks the homologous recombination between the diverged DNA sequences throughout the genome and thus prevent the stem cell to accumulate further genetic instability. Hematological malignancies and lymphoma arise due to chromosomal rearrangements because of loss of MMR proteins [33]. The efficient mismatch repair mechanisms engage the stem cells to undergo apoptosis when DNA is damaged. For example, hematopoietic stem cells show premature senescence (cellular aging) when they are exposed to ionizing 


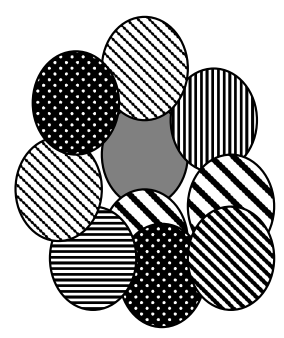

\section{Primary tumor with cancer stem cells}

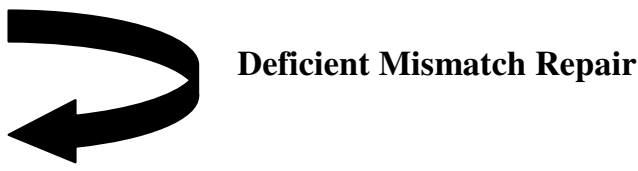

\section{Chemotherapy}

\section{Induction of cellular mechanisms} \& apoptosis

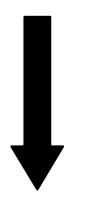

Cell death

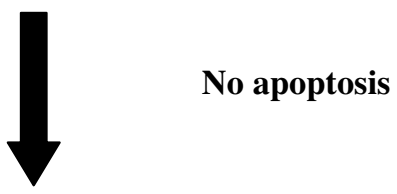

Tumor recurrence

\section{Figure 2}

Active mismatch repair system in primary tumors help in the induction of cell death after chemotherapy. Primary tumors containing heterogeneous population of tumor cells along with small \% of cancer stem cells (CSCs, represented by dark gray colored oval shape undergo chemotherapy. Presence of active mismatch repair induces cellular response followed by apoptosis, which lead to cell death. However, mismatch repair deficiency makes tumor cells insensitive to drug and it relapses.

radiation or busulfan [40]. In response to alkylation or oxidative DNA damage, the DNA MMR machinery directly or indirectly stimulates signal transduction, transcription factors, loss of cell cycle regulation that derive cell fate decision pathways including apoptosis. The cells with damaged DNA bases undergo G2 arrest in presence of hMLH1 as well as the checkpoint kinases ATR and Chk1 [41]. The stress kinase $\mathrm{p} 38$ is activated in presence of hMLH1 and its inhibition cause cells to bypass G2 arrest [42]. Cisplatin treated cells redistribute hPMS2 to the nucleus and its functional interaction with p73, a p53 related protein increases cell death [43]. Functional hMSH2 and hMLH1 also activates c-Abl, one of the proteins of p73 dependent apoptosis pathway $[44,45]$. The MMR proteins allow the cisplatin-induced initiation of G1 arrest by cyclin D1 degradation [46]. Defective MMR along with the mutated p53 response contributes to cisplatin resistance [38].

Most of the human cancers are identified having mismatch repair deficiency that result in defect in cell cycle and altered growth as in case of hematological malignancies. The defective MMR status in a damaged cell directly contributes to the resistant phenotype against the cytotoxic effects of chemotherapeutic drugs and thus these CSCs survive chemotherapy (Fig 2). The activation of DNA MMR system would help in inhibiting the survival mechanisms by raising the sensitivity of such cells to therapeutic drugs and reduce its tumor potential by arresting their growth. Owning to mass effect, progeny cancer cells still show the symptoms in the patients and therefore, the combinational therapy for the eradication of cancer stem cells and differentiated cells would be more effective. Antitumor treatment strategies selectively targeting the subset of tumor stem cells would be of clinical significance.

\section{Conclusion}

The maintenance of genomic stability is the prime requirement for the stem cell phenotype and its normal functioning. The increased mutation rate and absence of MMR may give rise to stem cell failure, a proliferative advantage and cancer stem cells formation. The cancer stem cells having MMR deficiencies make them insensitive to the treatments against the cytotoxic agents and would increase the risk of relapse and metastasis. The 
importance of MMR in designing the therapeutic strategies specifically targeting the tumor cells is being explored and pursued in the clinical trials.

\section{Competing interests}

The author(s) declare that they have no competing interests.

\section{Authors' contributions}

The manuscript was written and finalized by the author.

\section{References}

I. Gurdon JB: The developmental capacity of nuclei taken from intestinal epithelial cells of feeding tadpoles. J Embryol Exp Morphol 1962, 10:622-640.

2. Gurdon JB, Uehlinger V: 'Fertile' intestine nuclei. Nature 1966, 210:1240-124|.

3. Li F, Tiede B, Massague J, Kang Y: Beyond tumorigenesis: cancer stem cells in metastasis. Cell Res 2007, I7(1):3-14.

4. Dean M: Cancer stem cells: redefining the paradigm of cancer treatment strategies. Mol Interv 2006, 6(3):140-8.

5. Reese JS, Liu L, Gerson SL: Repopulating defect of mismatch repair-deficient hematopoietic stem cells. Blood 2003, 102(5):1626-33.

6. Oakley EJ, Van Zant G: Unraveling the complex regulation of stem cells: implications for aging and cancer. Leukemia 2007:I-10.

7. Pan CX, Zhu W, Cheng L: Implications of cancer stem cells in the treatment of cancer. Future Oncol 2006, 2(6):723-3I.

8. Al-Hajj M, Clarke MF: Self-renewal and solid tumor stem cells. Oncogene 2004, 23(43):7274-82.

9. Woodward WA, Chen MS, Behbod F, Rosen JM: On mammary stem cells. J Cell Sci 2005, I I 8(Pt I6):3585-94.

10. Moore KA, Lemischka IR: Stem cells and their niches. Science 2006, 3 I I(5769): I 880-5.

II. Al-Haij M, Wicha MS, Benito-Hernandez A, Morrison SJ, Clarke MF: Prospective identification of tumorigenic breast cancer cells. Proc Natl Acad Sci USA 2003, I00(7):3983-8.

12. Dean M: Cancer stem cells: Implications for cancer causation and therapy resistance. Discovery Medicine 2005, 5:78-282.

13. Shiraishi A, Sakumi K, Sekiguchi M: Increased susceptibility to chemotherapeutic alkylating agents of mice deficient in DNA repair methyltransferase. Carcinogenesis 2000, $21(10): 1879-83$

14. Reese JS, Qin X, Ballas CB, Sekiguchi M, Gerson SL: MGMT expression in murine bone marrow is a major determinant of animal survival after alkylating agent exposure. J Hematother Stem Cell Res 200I, I0(I): II5-23.

15. Park $Y$, Gerson SL: DNA repair defects in stem cell function and aging. Annu Rev Med 2005, 56:495-508.

16. Klungland $A$, Lindahl $T$ : Second pathway for completion of human DNA base excision repair: reconstitution with purified proteins and requirement for DNase IV (FENI). EMBO J 1997, 16:3341-48.

17. Lindahl T, Wood RD: Quality control by DNA repair. Science 1999, 286:1897-905

18. Valerie K, Povirk LF: Regulation and mechanisms of mammalian double-strand break repair. Oncogene 2003, 22(37):5792-812.

19. Bakkenist CJ, Kastan MB: DNA damage activates ATM through intermolecular autophosphorylation and dimer dissociation. Nature 2003, 21 (6922):499-506.

20. Jiricny J: Replication errors: challenging the genome. $E M B O$ J 1998, I 7:6427-6436.

21. Kolodner R: Biochemistry and genetics of eukaryotic mismatch repair. Genes Dev 1996, I0:1433-1442.

22. Sia EA, Kokoska RJ, Dominska M, Greenwell P, Petes TD: Microsatellite instability in yeast: dependence on repeat unit size and DNA mismatch repair genes. Mol Cell Biol I 997, 17:285।-2858.

23. Allen DJ, Makhov A, Grilley M, Taylor J, Thresher R, Modrich P, Griffith JD: Mut $\mathbf{S}$ mediates heteroduplex loop formation by a translocation mechanism. EMBO J 1997, 16:4467-4476.
24. Wheeler JMD, Bodmer WF: DNA mismatch repair genes and colorectal cancer. Gut 2000, 47:148-153.

25. Gu L, Hong Y, McCulloch S, Watanabe H, Li GM: ATP - dependent interaction of human mismatch repair proteins and dual role of PCNA in mismatch repair. Nuc Acids Res 1998, 26:1 $173-1178$.

26. Vaish M, Mittal $B$ : DNA mismatch repair, microsatellite instability and cancer. Ind J of Exp Biol 2002, 40:989-994.

27. Vaish M, Mandhani A, Mittal RD, Mittal B: Microsatellite instability in superficial urinary bladder tumors: A clinical significance. BMC Urol 2005, 5(I):2.

28. Wei K, Kucherlapati R, Edelmann W: Mouse models for human DNA mismatch-repair gene defects. Trends Mol Med 2002, 8(7):346-53.

29. DeWeese TL, Shipman JM, Larrier NA, Buckley NM, Kidd LR, Groopman JD, Cutler RG, te Riele H, Nelson WG: Mouse embryonic stem cells carrying one or two defective Msh2 alleles respond abnormally to oxidative stress inflicted by low-level radiation. Proc Natl Acad Sci USA 1998, 95(20): I I $15-20$.

30. Whiteside D, McLeod R, Graham G, Steckley JL, Booth K, Somerville MJ, Andrew SE: A homozygous germ-line mutation in the human MSH2 gene predisposes to hematological malignancy and multiple cafe-au-lait spots. Cancer Res 2002, 62(2):359-62.

31. Nelson WG, Kastan MB: DNA strand breaks: the DNA template alterations that trigger p53-dependent DNA damage response pathways. Mol Cell Biol I994, I4(3): 1815-23.

32. Wang XW, Vermeulen W, Coursen JD, Gibson M, Lupold SE, Forrester K, Xu G, Elmore L, Yeh H, Hoeijmakers JH, Harris CC: The XPB and XPD DNA helicases are components of the p53mediated apoptosis pathway. Genes Dev 1996, I0(10): I2 I9-32.

33. Abuin $A$, Zhang $H$, Bradley $A$ : Genetic analysis of mouse embryonic stem cells bearing Msh3 and Msh2 single and compound mutations. Mol Cell Biol 2000, 20(I): I49-57.

34. Claij N, van der Wal A, Dekker $M$, Jansen L, te Riele H: DNA mismatch repair deficiency stimulates $\mathrm{N}$-ethyl- $\mathrm{N}$-nitrosoureainduced mutagenesis and lymphomagenesis. Cancer Res 2003, 63(9):2062-6.

35. Toft NJ, Winton DJ, Kelly J, Howard LA, Dekker M, te Riele H, Arends MJ, Wyllie AH, Margison GP, Clarke AR: Msh2 status modulates both apoptosis and mutation frequency in the murine small intestine. Proc Natl Acad Sci USA I 999, 96(7):39II-5.

36. Fink D, Zheng H, Nebel S, Norris PS, Aebi S, Lin TP, Nehme A, Christen $R D$, Haas M, MacLeod $C L$, Howell $S B$ : In vitro and in vivo resistance to cisplatin in cells that have lost DNA mismatch repair. Cancer Res 1997, 57(10): 184|-5.

37. Claij N, te Riele H: Msh2 deficiency does not contribute to cisplatin resistance in mouse embryonic stem cells. Oncogene 2004, 23(I):260-6.

38. Branch P, Masson M, Aquilina G, Bignami M, Karran P: Spontaneous development of drug resistance: mismatch repair and p53 defects in resistance to cisplatin in human tumor cells. Oncogene 2000, I 9(28):3। 38-45.

39. Jordan CT, Guzman ML, Noble M: Cancer stem cells. N Engl J Med 2006, 355(I2): |253-6I.

40. Meng A, Wang Y, Brown SA, Van Zant G, Zhou D: lonizing radiation and busulfan inhibit murine bone marrow cell hematopoietic function via apoptosis-dependent and -independent mechanisms. Exp Hematol 2003, 3 I ( I 2): I 348-56.

41. Wang $Y$, Qin J: MSH2 and ATR form a signaling module and regulate two branches of the damage response to DNA methylation. Proc Natl Acad Sci USA 2003, I 00(26): 15387-92.

42. Hirose Y, Katayama M, Stokoe D, Haas-Kogan DA, Berger MS, Pieper RO: The p38 mitogen-activated protein kinase pathway links the DNA mismatch repair system to the G2 checkpoint and to resistance to chemotherapeutic DNA-methylating agents. Mol Cell Biol 2003, 23(22):8306-15.

43. Jascur T, Boland CR: Structure and function of the components of the human DNA mismatch repair system. Int J Cancer 2006, I I 9(9):2030-5.

44. Nehme A, Baskaran R, Aebi S, Fink D, Nebel S, Cenni B, Wang JY, Howell SB, Christen RD: Differential induction of c-Jun NH2terminal kinase and c-Abl kinase in DNA mismatch repairproficient and -deficient cells exposed to cisplatin. Cancer Res 1997, 57( (15):3253-7.

45. Gong JG, Costanzo A, Yang HQ, Melino G, Kaelin WG Jr, Levrero M, Wang JY: The tyrosine kinase c-Abl regulates $\mathrm{p} 73$ in apoptotic 
response to cisplatin-induced DNA damage. Nature 1999, 399(6738):806-9.

46. Lan Z, Sever-Chroneos Z, Strobeck MW, Park CH, Baskaran R, Edelmann W, Leone G, Knudsen ES: DNA damage invokes mismatch repair-dependent cyclin DI attenuation and retinoblastoma signaling pathways to inhibit CDK2. J Biol Chem 2002, 277( 10$): 8372-81$.

47. Bonnet D, Dick JE: Human acute myeloid leukemia is organized as a hierarchy that originates from a primitive hematopoietic cell. Nat Med 1997, 3(7):730-7.

48. Li C, Heidt DG, Dalerba P, Burant CF, Zhang L, Adsay V, Wicha M, Clarke MF, Simeone DM: Identification of pancreatic cancer stem cells. Cancer Res 2007, 67(3): 1030-7.

49. Uchida N, Buck DW, He D, Reitsma MJ, Masek M, Phan TV, Tsukamoto AS, Gage FH, Weissman IL: Direct isolation of human central nervous system stem cells. Proc Natl Acad Sci USA 2000, 97(26): |4720-5.

50. Singh SK, Clarke ID, Terasaki M, Bonn VE, Hawkins C, Squire J, Dirks PB: Identification of a cancer stem cell in human brain tumors. Cancer Res 2003, 63(I 8):582I-8.

5I. Fang D, Nguyen TK, Leishear K, Finko R, Kulp AN, Hotz S, Van Belle $\mathrm{PA}, \mathrm{Xu} X$, Elder DE, Herlyn M: A tumorigenic subpopulation with stem cell properties in melanomas. Cancer Res 2005, 65(20):9328-37.

52. Klein Walter M, Wu Bryan P, Zhao Shuping, Wu Hong, Klein-Szanto Andres JP, Tahan Steven R: Increased expression of stem cell markers in malignant melanoma. Modern Pathology 2007, 20:102-107.

53. Collins AT, Berry PA, Hyde S, Stower MJ, Maitland NJ: Prospective identification of tumorigenic prostate cancer stem cells. Cancer Res 2005, 65: 10946-1095I.

54. Prince ME, Sivanandan R, Kaczorowski A, Wolf GT, Kaplan MJ, Dalerba P, Weissman IL, Clarke MF, Ailles LE: Identification of a subpopulation of cells with cancer stem cell properties in head and neck squamous cell carcinoma. Proc Natl Acad Sci USA 2007, 104(3):973-8.

Publish with Bio Med Central and every scientist can read your work free of charge

"BioMed Central will be the most significant development for disseminating the results of biomedical research in our lifetime. "

Sir Paul Nurse, Cancer Research UK

Your research papers will be:

- available free of charge to the entire biomedical community

- peer reviewed and published immediately upon acceptance

- cited in PubMed and archived on PubMed Central

- yours - you keep the copyright

Submit your manuscript here:

http://www.biomedcentral.com/info/publishing_adv.asp
BioMedcentral 